\title{
Design and Development of Biometric Enabled Advanced Voting System
}

\author{
Aman Jatain, Yojna Arora, Jitendra Prasad, Sachin Yadav, Konark Shivam
}

\begin{abstract}
The focus of this paper is to design and development of a biometric enabled biometric electronic voting machine. The proposed biometric electoral voting system allows the user to scan fingerprint and iris so that his or her credentials can be compared to existing fingerprint and iris images already stored in the system's database. Counting is going on right away, making the voting process more efficient, faster and safer. This system requires the identification of the voter Aadhaar card, the voter's thumb impression as well as the iris image. Voter's complete data, including all voters' fingerprint and iris image, is collected and stored in the database. While voting, the voter gives their Aadhaar card details and puts eye in front of the iris camera and finger inside a fingerprint scanner, the system looks for the seal already provided in the data base, and then compares the iris image to authenticate the voter's identity. If the data matches, the system commands the voter to vote through the electronic voting machine. If the fingerprints do not match, the voting presiding officer looks for the registration, or the iris image does not match after the fingerprint match, the voter is not allowed to vote, consider it vote rigging.
\end{abstract}

KEYWORDS_Electronic voting machine, iris, fingerprint

\section{INTRODUCTION}

Now, democracy has become a crucial part of people's lives [3]. The depth of democracy is voting. The voting process must be reliable, and the voting record must be accurately and reasonably recorded. This is often accomplished using a biometric system.

\section{Manuscript Received April 21, 2020}

Aman Jatain, Department of Computer Science, Amity University, Gurgaon, Haryana, India (email: amanjatainsingh@gmail.com)

Yojna Arora, J, Department of Computer Science, Amity University, Gurgaon, Haryana, India

Jitendra Prasad, Department of Computer Science, Amity University, Gurgaon, Haryana, India

Sachin Yadav, Department of Computer Science, Amity University, Gurgaon, Haryana, India

Konark Shivam, Department of Computer Science, Amity University, Gurgaon, Haryana, India
The electronic selection system defines valid voting and provides a fast method of counting votes, which helps produce accurate results [1]. Furthermore, electronic voting systems can improve the voter identification process using biometric identification. Biometrics is becoming an important personal identification solution because biometric identifiers cannot be mistaken because they represent a person's identity [7]. Biometric identification refers to the use of iris, fingerprint, face, palm and speech features as biometric identifiers. Fingerprint matching and iris scanning may be the key to this process. This is a difficult problem, thanks to the differences in the many impressions of the equal finger and the specificity of the iris. Fingerprints are unique to each person and do not change over time. The person's iris has an unchanged appearance from birth to death [4]. The electoral system began in the eighteenth century, and so far, many proposals have been made for the electoral system. When designing an electronic election system, it is important to think about the ways in which voting jobs are often conducted electronically, without sacrificing the privacy of voters or presenting them with the possibility of fraud.

\section{RELATED WORK}

"Smart Voting" is used to identify people who are trying to vote a second time, and once the fingerprint print is scanned, authentication is complete, and the user is locked into login. Casted vote will be updated for each instance of time in the database. Selection results are published on the same day with high accuracy and efficiency [8]. One way to vote online without having to go to the "electronic voting machine using the internet" booth. It is the fastest and most insecure to access. The web voting process does not create an error. Foreign soldiers may also participate in elections [9]. The "Advanced Secure Voting System with IoT" describes the biometric process and the identity of the individual, so duplication is often identified [10]. "IoT based e-voting system" is a system used for long-term engagement. This will save time, money and energy for voters to win the booth. The result is easy and fast to display. It provides high data security [11]. It's time to increase the "voting systems distributed with IoT" voting percentage. This reduces duplicate voting errors. It reduces manpower. This reduces costs [13]. The "fingerprint-based smart voting system" gave an idea of good and fair voting with an easy and reliable voting system. The design of the "High Security Biometric Voting System", which brings 
one step closer to fair and safe elections, enables voters to have real-time access and a seamless voting experience [23]. "Safe and secure smart electronic voting machine using biometric", the fact in this paper is that it is more secure and accurate. [26].

\section{METHODOLOGY}

For the proposed voting method, we use a biometric system that uses multiple sources of biometric behavior [19]. This can be done by combining multiple features of an individual or multiple bio-extraction and matching algorithms running on the same biometrics. This system improves the accuracy of matching the data for the biometric system in the voting process. Since there is no way for any candidate to provoke government-issued biometric records before the election process, we use iris recognition and fingerprint scanning for accuracy and reasonable voting result.

\section{A. Iris Recognition}

Iris identification uses pattern recognition techniques based on high resolution and repulsive images of iris in the human eye. Iris [27] is a stable organ throughout its life. Therefore, it serves as a good biometric for establishing one's identity. Due to margin-of-error and speed, iris recognition is now the most reliable way to verify a person's identity.

\section{B. Fingerprints Recognition}

The human fingerprint is unique to each individual and is considered a kind of signature and verifies the identity of the individual [9]. It is one of the oldest and most widely used forms of biometric identification. A hill is defined as a single curved section, and a valley is the area between two adjacent ridges. [14] The Ridge Flow model provides 18 minutes of detection features, such as local stops.

\section{PROCESS}

\section{A. Registration}

This is a register page where voters, candidates and election commission officials can register themselves. These should provide the best basic information on what is known. All information entered on the website is stored in the relevant database. The Election Commission official has the right to accept a qualified consumer and a suitable candidate, otherwise he / she has the right to refuse their registration.

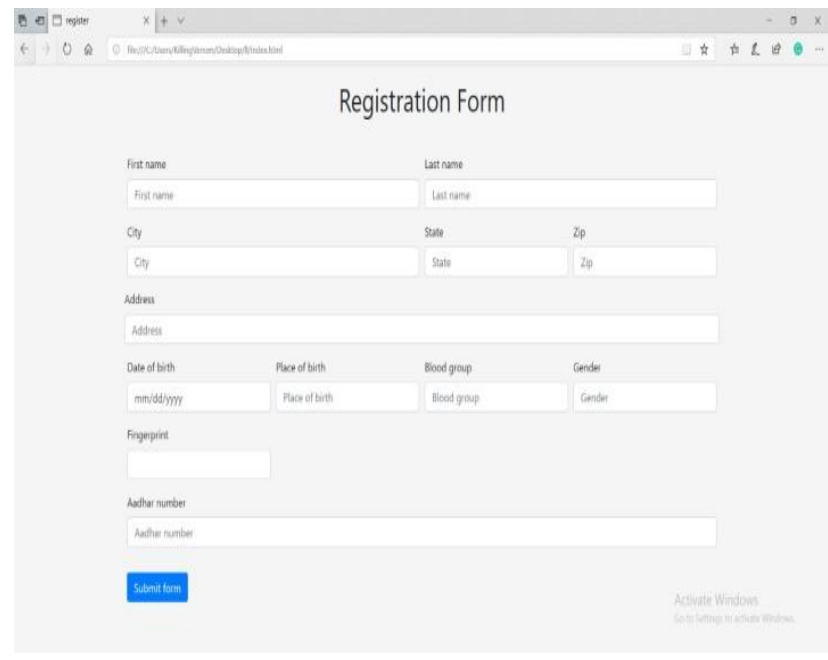

Fig. 1: Registration

\section{B. Verification}

The government id proofs will be verified thoroughly with the registered details, If the details match then the person gets registered successfully and gets his name listed in the election list otherwise the person is not eligible for voting in the elections [8].

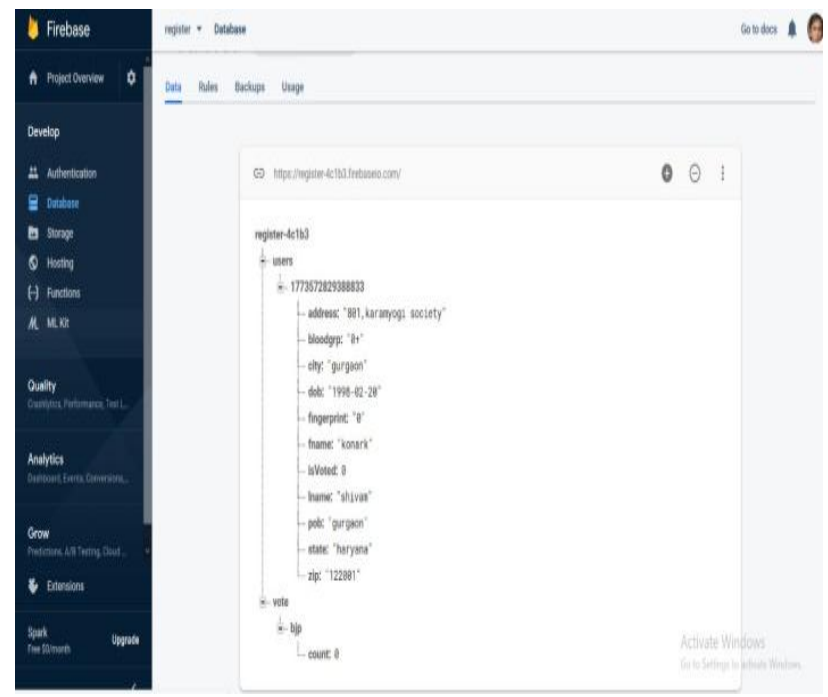

Fig. 2. Verification

\section{Machine setup}

With the attached iris and fingerprint sensors a vote casting machine will be placed in the voting area.

\section{Authentication}

The person who had registered successfully on the registration portal will be allowed to join the election. The voters arranged in the queue in front of polling booth will independently go for the scanning of iris as well as fingerprint. If the voter's identity matches with the dataset in the database, will be allowed to move forward [12].

\section{E. Voting}

Finally, authenticated voters will be allowed to cast vote. 


\section{FLOW DIAGRAM}

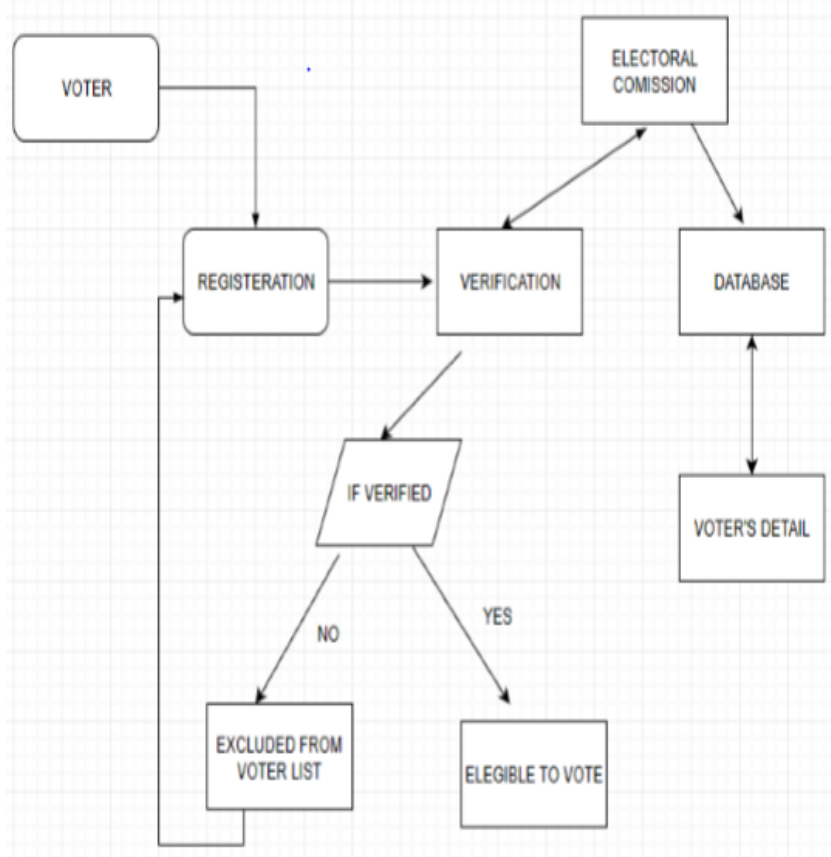

Fig 3. Voter's Registration

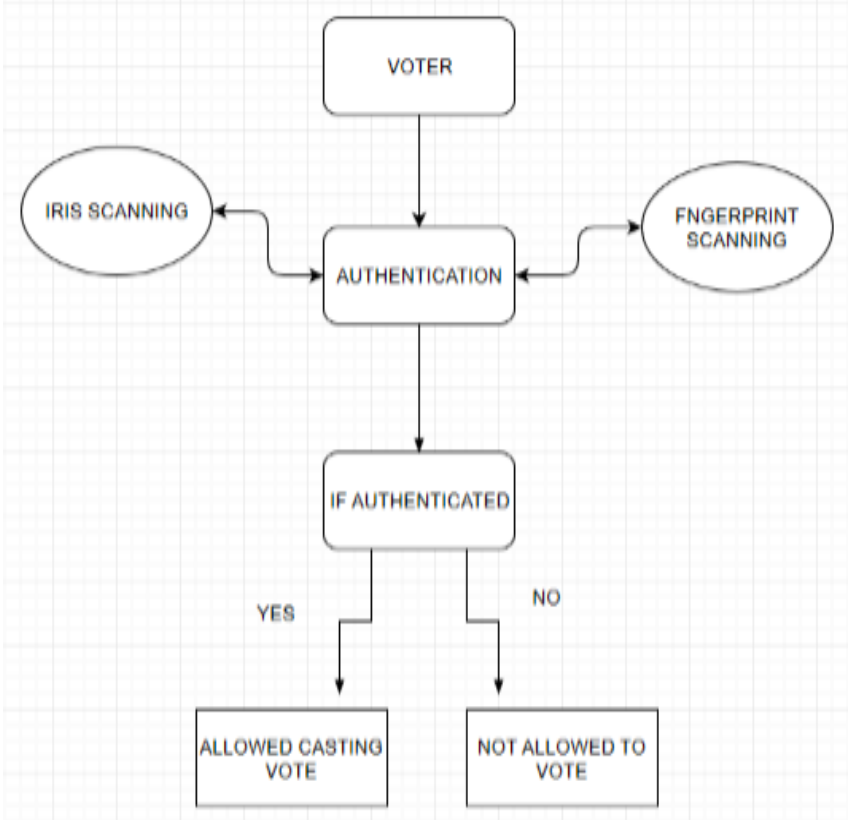

Fig 4.Voter's verification

\section{CONCLUSION}

Electronic voting machines in India are currently unsafe. There are many security issues in the system. The present design of EVM shows the optimal and unbiased result for the public for purely security purposes. The review suggested in this paper is a very secure biometric test voting machine. We have been able to get popular votes with the help of different sensor technologies, databases, and using some IoT in the voting machine, it can develop a better system to detect the biometric mis-match at all booth, which www.ijircst.org

creates alert in polling booth as well as the polling boards can communicated for the same.

\section{REFERENCES}

[1] Kumar DA, Ummal Sariba Begum T, A novel design of an electronic voting system using a fingerprint. Int $\mathrm{J}$ Innov Technol Creative Eng 1(1):12-19, 2011

[2] Jacobi RP, Trindade F, de Carvalho JPA, Cantanhede $\mathrm{R}$ JPEG decoding in an electronic voting machine. In: IEEE 13th symposium on integrated circuits and systems design, pp 177-182, 2000

[3] Agarwal H, Pandey GN Online voting system for India based on AADHAAR ID. In: 11th international conference on ICT and knowledge engineering (ICT\&KE), pp 1-4, 2013

[4] Ali SM, Mehmood CA, Khawja A, Nasim R, Jawad M, Usman S, Khan S, Salahuddin S, Ihsan MA Micro-controller based smart electronic voting machine system. In: IEEE international conference on electro/information technology (EIT), pp 438-442, 2014

[5] Hasan SM, Anis AM, Rahman H, Alam JS, Nabil SI, Khalilur Rhaman M Development of electronic voting machine with the inclusion of near field communication ID cards and biometric fingerprint identifier. In IEEE 17th international conference on computer and information technology (ICCIT), pp 383-387, 2014

[6] Kumar DA, Ummal Sariba Begum T Electronic voting machine-a review. In: IEEE international conference on pattern recognition, informatics and medical engineering (PRIME), pp 41-48, 2012

[7] Anandaraj S, Anish R, Devakumar PV Secured electronic voting machine using biometric. In: IEEE international conference on innovations in information, embedded and communication systems (ICIIECS), pp 1-5, 2015

[8] Kalaiselvi, Fabio Trindade VK, de Carvalho JPA, Cantanhede R Smart voting. In: Second international conference on computing and communications technologies(ICCCT'17), pp 1-10, 2017

[9] Gawhale S, Mulik V, Patil P, Raut N IOT based E-voting system. Int J Res Appl Sci Eng Technol (IJRASET) 5(5), 2017

[10] Nithya S, Ashwin C, Karthikeyan C, Ajith Kumar M Advanced secure voting system with IoT. Int J Eng Comput Sci 5(3):33-37, 2016

[11] Devgirikar SJ, Deshmukh SA, Paithankar VP, Bhawarkar NB Advanced electronic voting machine using internet of things (IOT). In: 2nd national conference recent innovations in science and engineering (NC-RISE 17), vol 5, no 9, pp 83-85, 2017.

[12] Santhosh M, Kavitha S, Keerthana R, Suganya L, Krishnakumar S Electronic voting machine using internet. Int J Commun Comput Technol 4(2), 2016.

[13] Channakeshava RN Distributed voting system using IOT. Int J Innov Res Comput Commun Eng 5(2), 2017 
[14] Khan MA, Salah K IoT security: review, blockchain solutions, and open challenges. Future Gener Comput Syst 82:395-411, 2018

[15] Coulter R, Pan L Intelligent agents defending for an IoT world: a review.Computer Security 73:439-458, 2019

[16] Sanjay Kumar, Manpreet Singh," Design of a secure electronic voting system using fingerprint technique", IJCSI International Journal of Computer Science Issues, Vol. 10, Issue 4, No 1, July 2013

[17] Longe O. L.a, Ayofe T Ab., Akporherhe O. A,’ Design and Implementation of Biometric Voting System for Tertiary Institutions in Nigeri", International Conference of Science, Engineering \& Environmental Technology (ICONSEET), 3(9): 60-65, ISSN 0794-9650, 2018

[18] Andreu Riera Jorba, José Antonio Ortega Ruiz, Paul Brown," Advanced Security to Enable Trustworthy Electronic Voting", Scytl Online World Security, S.A. Entença, 95, 4-1 08015 Barcelona (Spain)

[19] D.Krishna, T.Hemalatha, G.Dhana Mani Shankar, K.Bala Krishna, V.Bala Subhramanyam,"Aadhar based Electronic Voting System and Providing Authentication", ISSN: 2250-3676 [IJESAT] [International Journal of Engineering Science \& Advanced Technology] Volume-4, Issue-2, 237-240

[20] Md. Murshadul Hoque," A Simplified Electronic Voting Machine System", International Journal of Advanced Science and Technology Vol.62, pp.97-102, 2014

[21] M. Mesbahuddin Sarker, Md. Ariful Islam Shah, Tajim Md. Niamat Ullah Akhund, Md. Sharif Uddin ," An Approach of Automated Electronic Voting Management System for Bangladesh Using Biometric Fingerprint ", International Journal of Advanced Engineering Research and Science (IJAERS)

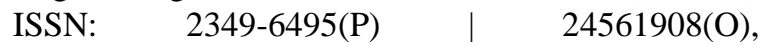
[Vol-3,Issue-11,Nov-2016]

[22] M.Sudhakar, B.Divya Soundarya Sai," Biometric System Based Electronic Voting Machine Using Arm9 Microcontroller", IOSR Journal of Electronics and Communication Engineering (IOSR-JECE) e-ISSN: 2278-2834,p- ISSN: 2278-8735.Volume 10, Issue 1, PP 57-65, Ver. II (Jan - Feb. 2015)

[23] N. Narayanan, Ch. Surya Pradeep, Piyush Gulati, G. Raj Bharath, S.Nivash," Design of Highly Secured Biometric Voting System", International Journal of Engineering and Advanced Technology (IJEAT) ISSN: 2249 - 8958, Volume-8 Issue-5S3, July, 2019

[24] Mary Varsha Peter, V.Priya, H.Petchammal and N.Muthukumaran," Finger Print Based Smart Voting System ", Asian Journal of Applied Science and Technology (AJAST) (Open Access Quarterly International Journal) Volume 2, Issue 2, Pages 357361, 2018

[25] M.Thangamani, S.Shunmathy, S.Backi yalakshmi, P.T.Aiswariya, K.Priyadharshini," A SECURITY BASED VOTING SYSTEMUSING BIOMETRIC ”, Pundir Manju Baisoya Int. Journal of Engineering Research and Applications www.ijera.com ISSN:
2248-9622, Vol. 6, Issue 3, pp.44-50, (Part - 3) March 2016

[26] Ganapathi T, Sathishkumar D," SAFE AND SECURE SMART ELECTRONIC VOTING MACHINE USING BIOMETRIC", International Research Journal of Engineering and Technology (IRJET), e-ISSN: 2395-0056 p-ISSN: 2395-0072 Volume: 06 Issue: 03 | Mar 2019

[27] Shital A PAtil , Praveen G Kote ," IRIS Detection in Voting System" International Journal for Research in Applied Science \& Engineering Technology (IJRASET), www.ijraset.com Volume 3 Issue VIIIIC Value: 13.98 ISSN: 2321-9653, August 2015. 